\title{
Arterial switch with full-flow cardiopulmonary bypass and limited circulatory arrest: Neurodevelopmental outcome
}

Tom R. Karl, MD

Suzanne Hall, RN ${ }^{b}$

Geoff Ford, MD ${ }^{\mathrm{b}}$

Elaine A. Kelly, MS ${ }^{b}$

Christian P. R. Brizard, MD

Roger B. B. Mee, FRACS

Robert G. Weintraub, MB, BS ${ }^{b}$

Andrew D. Cochrane, FRACS ${ }^{b}$

David Glidden, PhD $^{\mathrm{d}}$
From the Division of Pediatric Cardiothoracic Surgery and the Department of Epidemiology and Biostatistics, ${ }^{\mathrm{d}}$ UCSF School of Medicine, San Francisco, Calif; the Cardiac Surgical Unit, ${ }^{\text {b }}$ Royal Children's Hospital, Melbourne, Australia; and the Department of Pediatric and Congenital Heart Surgery, ${ }^{\mathrm{c}}$ Cleveland Clinic Foundation, Cleveland, Ohio.

Read at the Eighty-first Annual Meeting of The American Association for Thoracic Surgery, San Diego, Calif, May 6-9, 2001.

Received for publication May 3, 2001; revisions requested Aug 10, 2001; final revisions received May 20, 2003; accepted for publication June 25, 2003.

Address for reprints: Tom R. Karl, MD, UCSF Children's Hospital S-549, Division of Pediatric Cardiothoracic Surgery, 513 Parnassus Ave, San Francisco, CA 941430118 (E-mail: karlt@surqery.ucsf.edu).

J Thorac Cardiovasc Surg 2004;127:213-22 $0022-5223 / \$ 30.00$

Copyright $(9) 2004$ by The American Association for Thoracic Surgery

doi:10.1016/j.jtcvs.2003.06.001
Objectives: Neonatal cardiac surgery has been associated with unfavorable neurodevelopmental events. We investigated a patient cohort operated on predominantly with full-flow cardiopulmonary bypass $\left(150 \mathrm{~mL} \cdot \mathrm{kg}^{-1} \cdot \mathrm{min}^{-1}, \alpha\right.$-stat, $\alpha$-blockade, median arrest $=6$ minutes, temperature of $22^{\circ} \mathrm{C}$ ) as the major support strategy for neonatal arterial switch operations (transposition of the great arteries and intact ventricular septum).

Methods: Seventy-four patients and "best-friend" control subjects were assessed 109 months (range, 48-166 months) postoperatively with general medical and neurologic evaluation, IQ testing, formal movement scores, and detailed parentteacher behavioral-social reports. Fetal, neonatal, and perioperative data were collated.

Results: The prevalence of perioperative seizures was $6.8 \%$ (4/5 cases occurring preoperatively). The incidence of all perioperative neurologic abnormalities was $20 \%$. Patients who had a neurologic event were (as a group) older at the time of operation and had a lower arterial blood $\mathrm{pH}$ before the operation. Selected perioperative factors (not related directly to cardiopulmonary bypass variables) predicted early (before discharge) neurologic outcome in a multivariate model. At late assessment, patients were more likely than control subjects to have a mild neurologic abnormality $(P=0.002)$. Full-scale IQ scores (Wechsler Preschool and Primary Scale of Intelligence and Wechsler Intelligence Scale for Children-Third Edition) were higher in control subjects $(101.9[\mathrm{SD}=13]$ vs 108.6 [SD $=12], P$ $=.0007)$, with both groups having scores greater than the population-based test means. Full-scale IQ scores related most significantly to years of paternal education $(\beta=1.51, P=.0078)$ but were also influenced by perioperative neurologic abnormalities, birth weight, and circulatory arrest time. Patients had higher motor impairment scores (Movement Assessment Battery) than control subjects $(P=$ .0004). Parents (Achenbach Child Development Checklist) assigned higher total social-behavioral competence scores to control subjects $(P=.05)$. Teachers (Achenbach Teacher Report Form) suggested that patients were more likely to be perceived as having various speech and expressive language problems, as well as minor behavioral problems.

Conclusion: With the perioperative strategies used, not all survivors can be considered (neurodevelopmentally) normal at late follow-up, although the risk of important impairment is low. Perioperative events might have long-term prognostic value. On the basis of this study and published data regarding other strategies, continued application of full-flow cardiopulmonary bypass is justified, with the proviso that further investigation is required. 


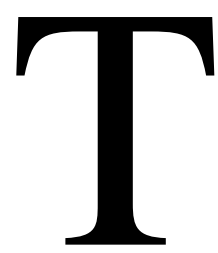

he excellent hemodynamic results of the arterial switch operation (ASO) have appropriately shifted attention from survival (as the sole outcome indicator) to late neurodevelopmental status. ${ }^{1-10}$ Much of the latter work has been directed toward analysis of the influence of perioperative events, with emphasis on the conduct of cardiopulmonary bypass (CPB).

Some neonates undergoing cardiac surgery might have subtle deficiencies when assessed later in life with sensitive neurodevelopmental instruments. ${ }^{9,11-15}$ Moreover, for patients who have had deep hypothermia and circulatory arrest (DHCA), the outcome might be worse than that for control subjects operated on with low-flow hypothermic CPB or other strategies. Perioperative seizure activity is related to the use and duration of circulatory arrest and might predict late neurologic problems and poorer results of childhood intelligence tests. ${ }^{1,2,10,13}$ Analysis and comparison of results has been somewhat difficult because of the spectrum of severity (anatomic and physiologic) of the lesions investigated, variability in follow-up time, diversity in perioperative strategy, preoperative status, and other factors.

Patients with transposition of the great arteries (TGA) and intact ventricular septum (IVS) undergoing ASO constitute an ideal cohort for a neurodevelopmental outcome study. The patients are neonates, anatomically similar, and have a low incidence of associated abnormalities or syndromes. In our own practice the surgical indications and strategies have been quite standardized since the early 1980s. The operative mortality is less than $1 \%$ in many large centers (including the Royal Children's Hospital during the study period), and the need for reoperation has been rare. ${ }^{16-18}$ Likewise, late mortality has been unusual. Finally, the relatively normal postoperative physiology allows one to better segregate and assess the perioperative factors affecting long-term outcome.

ASO for TGA and IVS can be performed safely with full-flow $\left(150 \mathrm{~mL} \cdot \mathrm{kg}^{-1} \cdot \mathrm{min}^{-1}\right) \mathrm{CPB}$, limiting the circulatory arrest time to what is required to close the atrial septal defect. This latter method has been our strategy since the introduction of the ASO in Melbourne in the early 1980s. ${ }^{16,19}$ Taking into account the published results of ASO with reduced flow or DHCA as the primary CPB strategy, it might be logically suggested (although unproved) that if low-flow CPB is better than DHCA, then full-flow CPB might be better than either strategy. We analyzed early and late outcome for our own cohort operated on primarily with full-flow CPB. We include the first report of late neurodevelopmental results for patients with TGA operated on with this strategy.

In the current study we address the following questions:

1. How do survivors of the ASO for TGA-IVS compare with their peers who did not need cardiac surgery?
2. Can we predict late neurodevelopmental outcome with information that is available to us perioperatively, allowing us to modify future treatment strategies to the patients' benefit?

\section{Methods}

With the approval of the Royal Children's Hospital Ethics in Research Committee, we invited ASO survivors who were at least 48 months of age, as well as their parents and teachers, to participate in our study. We included all consenting families available for interview and assessment in the Australian states of Victoria, South Australia, and Tasmania. Children from more distant areas (eg, Western Australia, Northern Territories, and Southeast Asia) could not be included because of logistic and funding considerations. We were therefore able to assess $40 \%$ of all eligible patients and $90 \%$ of eligible patients residing within the state of Victoria. "Best-friend" control subjects were nominated by patients or their families and were found to be well matched (see the "Results" section). When possible, children and control subjects were assessed concurrently.

Data collection was performed by a team including cardiac surgeons, a cardiac intensive care unit (ICU) nurse who also served as study coordinator, a developmental pediatrician, a pediatric cardiologist, and a pediatric neuropsychologist-speech pathologist. Standard, well-validated neurodevelopmental tests were administered, and a general medical and neurologic evaluation was performed (Figure 1 and Appendix). Fetal, neonatal, and perioperative data were collated from hospital and departmental databases, as well as from direct medical chart review. Parents and teachers were queried regarding child behavioral and social development by using standardized forms and a standardized interviewing format (Appendix). Data analysis was performed in a number of ways, according to the type of variables under consideration. Normality of distribution of continuous variables was tested with the Kolmorogov-Smirnov method. Normally distributed continuous variables were compared by using the Student $t$ test. Nonnormally distributed variables were compared by using Mann-Whitney nonparametric analysis. Fisher and $\chi^{2}$ tests were used for univariate comparison of proportional outcome. All tests were 2-tailed, and data were paired whenever appropriate. Analysis of the Teacher Report Form data was performed by using a test for paired proportions. ${ }^{20}$ To create a predictive model for IQ, we used multivariate linear regression after mathematic selection of candidate variables. All confidence intervals (CIs) are 95\% unless otherwise stated. Statistical software used included Prism 3.0, Instat, and Statmate (all from Graphpad Software, Inc, San Diego, Calif); NCSS (Statistical Software, Kaysville, Utah); and Stata (Release 7; Stata Corp, College Station, Tex). The power of this analysis to detect a difference of $0.5 \mathrm{SD}$ in IQ score (see below) was $85 \%$ at $P=.05$.

\section{Patients}

Seventy-four patients and 74 "best-friend" control subjects were available for this study. The patients had all undergone ASO for TGA-IVS between 1988 and 1994 at a median age of 9 days (range, 0-118 days). Patients with more complex forms of TGA (ventricular septal defect, arch obstruction, and Taussig-Bing heart) were not included, in order to minimize confounding tech- 


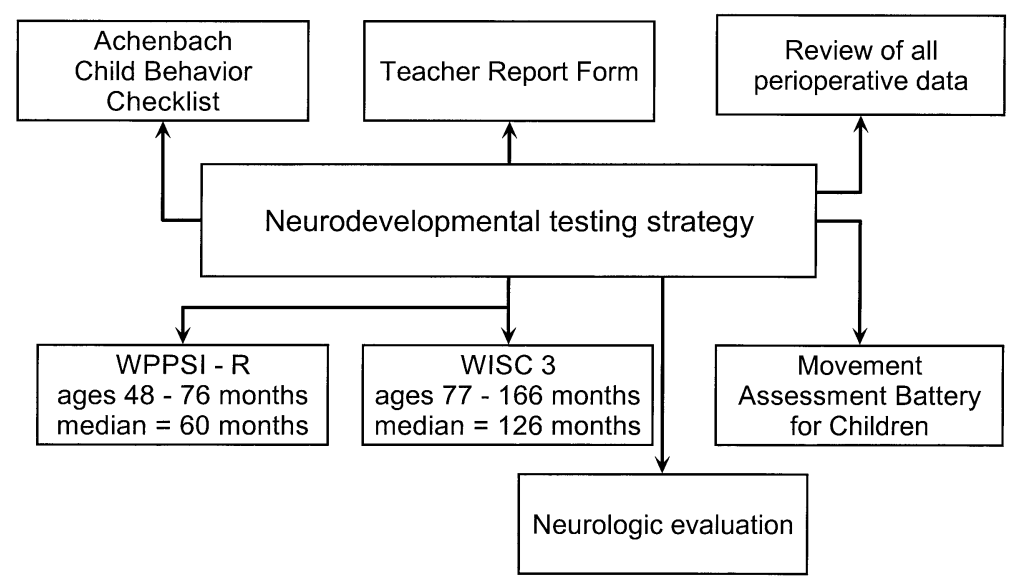

Figure 1. Assessment battery used to determine early and late neurodevelopmental outcome for neonates undergoing the ASO for TGA-IVS. See the Appendix for further explanation of the instruments used.

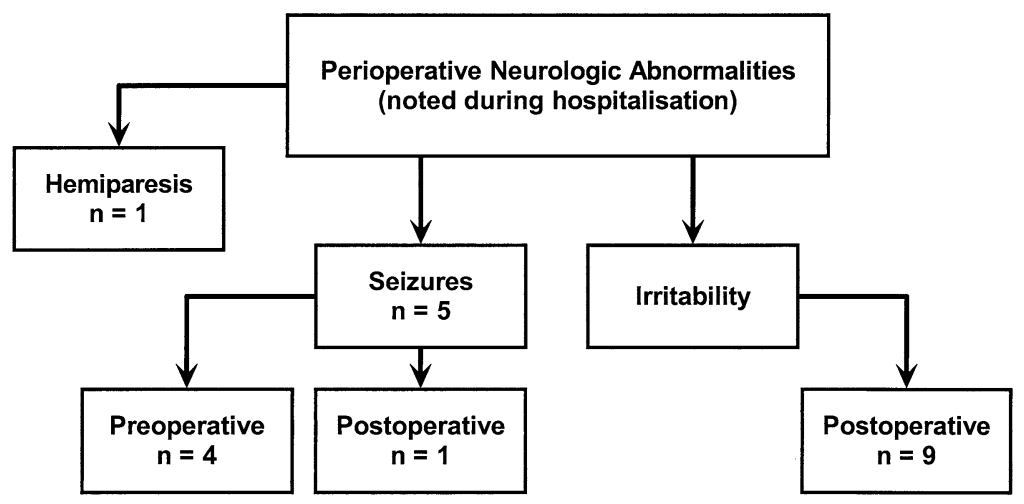

Figure 2. Neurologic abnormalities noted after the ASO for TGA-IVS before hospital discharge. The overall incidence was $20 \%(95 \% \mathrm{Cl}, 12 \%-31 \%)$. Four of 5 patients with clinical seizure activity also had the abnormality before the operation.

nical, anatomic, and age-related variables. Mean gestational age was 39.6 weeks (SD 1.5), and mean weight at the time of ASO was $3.42 \mathrm{~kg}$ (SD 0.46). Preoperatively, the diagnosis was established with clinical assessment and echocardiography. Angiography and catheter-based hemodynamic studies were not usually used. Prostaglandin $\mathrm{E}_{1}\left(\mathrm{PGE}_{1}\right)$ was administered if oxygenation was not acceptable (hemoglobin $\mathrm{SO}_{2}<80 \%$ ), and balloon atrial septostomy was routinely performed preoperatively. The emphasis was adequate preoperative resuscitation rather than emergency operation. Preoperative establishment of enteral feeding was considered important for patients not receiving $\mathrm{PGE}_{1}$.

Patients were operated on by using a uniform intent-to-treat strategy involving a CPB flow of $150 \mathrm{~mL} \cdot \mathrm{kg}^{-1} \cdot \mathrm{min}^{-1}$ at a minimum temperature of $22^{\circ} \mathrm{C}$, with an alpha-stat $\mathrm{pH}$ strategy during hypothermia. Hemoglobin was maintained at 8 to $9 \mathrm{~g} / \mathrm{dL}$ during $\mathrm{CPB}$, and fresh ( $<24$ hours old) heparinized (noncitrated) blood was used in the CPB circuit prime. We also used pre-CPB $\alpha$-blockade with phenoxybenzamine $(1 \mathrm{mg} / \mathrm{kg}$ ) and a single dose of methylprednisolone $(30 \mathrm{mg} / \mathrm{kg})$ in the priming solution. CPB was established with aortic and right atrial cannulation. Flow was
$150 \mathrm{~mL} \cdot \mathrm{kg}^{-1} \cdot \min ^{-1}$ for all temperatures $\left(22^{\circ} \mathrm{C}-37^{\circ} \mathrm{C}\right)$, and our intention was to avoid circulatory arrest, except for the period required to close the atrial septal defect (median, 6 minutes; range, 3-40 minutes; 25 th percentile, 5 minutes; 75 th percentile, 8 minutes). This arrest period was necessary because of the routine use of single atrial cannulation during the study period. The median crossclamp time was 60 minutes (range, 39-101 minutes; 25th percentile, 49 minutes; 75 th percentile, 68 minutes), and the median CPB time was 117 minutes (range, 78-275 minutes; 25th percentile, 106 minutes; 75th percentile, 130 minutes).

Postoperative management included sedation with a continuous morphine infusion $\left(10-60 \mu \mathrm{g} \cdot \mathrm{kg}^{-1} \cdot \mathrm{h}^{-1}\right)$ and paralysis with intermittent pancuronium injections $(0.1-0.15 \mathrm{mg} / \mathrm{kg})$ for 12 to 48 hours. Peritoneal dialysis was used as required for control of fluid balance, metabolic milieu, and core temperature. ${ }^{16,19}$ Early cessation of narcotics and muscle relaxants was encouraged to allow ventilator independence (median, 3 days; range, 1-18 days) and enteral feeding. We generally continued $\alpha$-blockade with phenoxybenzamine $(0.5 \mathrm{mg} / \mathrm{kg}$ every 12 hours $)$ for 3 days. The median time in the ICU during the course of this study was 3 days. 
TABLE 1. Variables examined in patients who had a neurologic event and those who did not (upper box)

\begin{tabular}{|c|c|c|c|}
\hline Variable & $\begin{array}{c}\text { No neurologic } \\
\text { event }\end{array}$ & $\begin{array}{l}\text { Neurologic } \\
\text { event }\end{array}$ & $P$ value \\
\hline Birth weight $(\mathrm{g})$ & 3441 (57) & $3353(146)$ & .5 \\
\hline Age at operation (d) & $11.5(2.1)$ & $13.8(1.9)$ & .59 \\
\hline Lowest $\mathrm{P}_{2}$ preop (mm) & $24.8(0.93)$ & $23.3(1.6)$ & .44 \\
\hline Lowest $\mathrm{P}_{2}$ postop (mm) & $70.2(1.3)$ & $73.7(2.5)$ & .23 \\
\hline Lowest $\mathrm{pH}$ preop & $7.3(0.01)$ & $7.25(.03)$ & .04 \\
\hline Lowest pH postop & $7.38(.008)$ & $7.39(.014)$ & .56 \\
\hline Lowest mean BP preop & $39.1(0.48)$ & $37.3(1.2)$ & .12 \\
\hline Lowest mean BP postop & $38.4(0.5)$ & $39.6(0.65)$ & .26 \\
\hline Gestational age (wk) & $39.6(.12)$ & $39.5(0.5)$ & .94 \\
\hline Apgar score $1 \mathrm{~min}$ & $6.9(0.2)$ & $6.1(0.4)$ & .07 \\
\hline Apgar score $5 \mathrm{~min}$ & $8.5(0.1)$ & $8.3(0.2)$ & .54 \\
\hline CPB time (min) & $117(2.4)$ & $135(11.2)$ & .13 \\
\hline Circulatory arrest time (min) & $7.9(0.8)$ & $5.7(0.4)$ & .02 \\
\hline Aortic clamp time (min) & $60.3(1.7)$ & $57.8(3)$ & .5 \\
\hline Days in ICU postop & $3(0.1)$ & $5.9(1.5)$ & .07 \\
\hline Days ventilated & $2.6(0.15)$ & $4.8(1.3)$ & .08 \\
\hline Time septostomy-ASO (d) & $9.2(1.5)$ & $12.1(2.2)$ & .37 \\
\hline Transport time to $\mathrm{RCH}(\mathrm{h})$ & $35.4(9.1)$ & $26.4(9.2)$ & .63 \\
\hline Days in hospital & $17.7(0.82)$ & $22(2)$ & .03 \\
\hline Sepsis during hospitalization & $7 / 59$ & $6 / 15$ & .02 \\
\hline \multirow[t]{2}{*}{$\mathrm{PGE}_{1}$ at time of $\mathrm{ASO}$} & $4 / 59$ & $4 / 15$ & .05 \\
\hline & & & $P$ \\
\hline Variable & Odds ratio & $95 \% \mathrm{CI}$ & (vs $\beta=0$ ) \\
\hline $\mathrm{PGE}_{1}$ & 10.21 & $1.08-96.64$ & .043 \\
\hline Sepsis & 9.05 & $1.42-57.54$ & .020 \\
\hline Low pH postop & $1.27 e+07$ & $2.31-31.88$ & .039 \\
\hline Days in ICU & 2.57 & $1.31-5.03$ & .006 \\
\hline
\end{tabular}

Unpaired $t$ tests were used for continuous variables. For contingency tables, we used the Fisher exact method. The lower box presents a logistic regression analysis with the 3 univariables, which had a $P$ of less than .05 . The odds ratio for intensive care unit days could be compounded to have a strong effect, but in a retrospective study, the question of cause versus effect is always present. preop, Preoperative; postop, postoperative; $B P$, blood pressure; $C P B$, cardiopulmonary bypass; $I C U$, intensive care unit; ASO, arterial switch operation; $R C H$, Royal Children's Hospital; $\mathrm{PGE}_{1}$, prostaglandin $\mathrm{E}_{1}$.

\section{Results}

\section{Perioperative Observations}

In the perioperative period (defined as birth to hospital discharge), 15 (20\%; 95\% CI, 12\%-31\%) of 74 patients were noted to have some type of neurologic abnormality (Figure 2). Electroencephalographic (EEG) monitoring was not routinely used during the study period, and therefore the true incidence of ictal cerebral activity is unknown (and thus probably underestimated). However, clinical seizures (defined as spontaneous repetitive or sustained abnormal facial extremity or generalized movements) were observed in 5 $(6.8 \%$; $95 \%$ CI, $2 \%-15 \%)$ of 74 patients. Moreover, in 4 of 5 patients the clinical seizures were first observed preoperatively. Various clinically relevant fetal and perioperative variables were compared for patients with neurologic ab- normalities and those without. The analysis included variables relating to the conduct of $\mathrm{CPB}$, including duration of circulatory arrest, duration of $\mathrm{CPB}$, and ischemic time. Patients who had a neurologic event (as a group) had a lower arterial blood $\mathrm{pH}$ before the operation. Some perioperative events (use of $\mathrm{PGE}_{1}$ immediately before the operation, sepsis, low $\mathrm{pH}$ postoperatively, and longer ICU stay) were associated with early (predischarge) neurologic outcome in a multivariate model (Table 1). No variable directly related to the conduct of CPB had predictive value. Likewise, the detection of clinical perioperative seizures was not predictive of epilepsy at later follow-up. The latter problem was observed in a single child, who was not noted to have perioperative seizures. Likewise, perioperative seizure activity as an isolated event did not significantly predict poorer performance on later IQ testing (see below).

\section{Later Observations}

The median patient age at the time of late assessment was 109 months (range, 48-166 months). The "best-friend" control subjects were compared with the patient cohort to see whether bias might have been introduced. We found the 2 groups to be well matched in relation to family, social, medical, and other aspects (Table 2).

Patients and control subjects were compared in various other respects to assess general development, quality of life, and freedom from medical treatment. Height and weight percentiles were similar for the 2 groups (58.7\% vs $62.6 \%$ $[P=.09]$ and $55.1 \%$ vs $59.1 \%[P=.47]$, respectively). Four of 74 patients and 3 of 74 control subjects required medication on a chronic basis $(P=1.0)$, none for cardiac indications. Nine of 74 control subjects and 15 of 74 patients had required hospitalization after the neonatal period $(P=.26)$. Five of the 15 patients had a cardiac indication for their hospitalization. Fifteen of 74 control subjects and 14 of 74 patients had required medical treatment for extracardiac problems $(P=1.0)$. Four of 74 control subjects and 11 of 74 patients were considered to be hyperactive $(P=$ .1). Six of 74 patients but no control subjects had some type of chest wall deformity $(P=.03)$.

Percentile ranks for head circumference were compared in patients and control subjects and were found to be lower in the former group (48.7\% [SD 24] vs $60.7 \%$ [SD 23.4]; $P$ $=.004$, paired $t$ test).

Patients and control subjects were assessed for the presence of neurologic deficits at late follow-up. Everyday motor skills of both patients and control subjects were evaluated according to the Movement Assessment Battery for Children (Appendix). The patients' overall manual dexterity scores were higher (ie, worse) for patients (4.99 [SD 0.35] vs 3.4 [SD 0.31], $P=.002$ ), and patients also tended to have worse total static-dynamic balance scores (2.74 [SD 0.36] vs 1.88 [SD 0.29], $P=.03$ ). The total motor impairment 
TABLE 2. Comparison of various familial, social, and medical aspects of patients and "best-friend" control subjects

\begin{tabular}{|c|c|c|c|}
\hline Factor & TGA & $\begin{array}{c}\text { Control } \\
\text { subjects }\end{array}$ & $\boldsymbol{P}$ \\
\hline Maternal age (y) & $29.6( \pm 4.7)$ & $28.7( \pm 4.1)$ & .21 \\
\hline Birth weight $(\mathrm{kg})$ & $3.42( \pm 0.46)$ & $3.41( \pm 0.45)$ & .82 \\
\hline Age at evaluation (mo) & $109.7( \pm 34.3)$ & $108.5( \pm 35.5)$ & .44 \\
\hline Maternal education (y) & $13.1( \pm 2.5)$ & $12.4( \pm 2.2)$ & .08 \\
\hline Paternal education (y) & $12.4( \pm 2.7)$ & $12.3( \pm 2.3)$ & .84 \\
\hline Maternal occupation score & $2.7( \pm 2.4)$ & $2.2( \pm 2.5)$ & .27 \\
\hline Paternal occupation score & $4.7( \pm 1.7)$ & $4.5( \pm 1.9)$ & .46 \\
\hline No. of children & $2.7( \pm 1.0)$ & $2.4( \pm 0.9)$ & .11 \\
\hline Birth order & $2(1-5)$ & $2(1-5)$ & .16 (Mann-Whitney) \\
\hline Family structure & $1(1-4)$ & $1(1-4)$ & .91 (Mann-Whitney) \\
\hline Languages spoken in home & $1(1-3)$ & $1(1-3)$ & 1.34 (Mann-Whitney) \\
\hline Medications & $4 / 74$ & $3 / 74$ & 1.0 (Fisher) \\
\hline Seizures (presently) & $1 / 74$ & $0 / 74$ & - \\
\hline
\end{tabular}

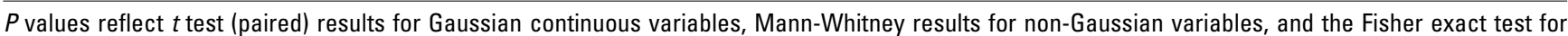
contingency tables.

score was higher for patients than for control subjects (9 [SD 0.7] vs 5.9 [SD 0.51], $P=.0004$ ), but once again, scores for both groups fell into a normal range. No deficits were encountered in either group for sensory testing or proprioception. Eight patients and 8 control subjects had minor abnormalities of visual acuity. Hearing was mildly impaired in 1 patient and no control subjects. Two control subjects and no patients had mild past-pointing. Thus the history of neonatal cardiac repair did not figure importantly in identification of a clinical problem in the specific areas of motor function assessed.

Intelligence testing was performed by using the Wechsler Preschool and Primary Scale of Intelligence or Wechsler Intelligence Scale for Children-Third Edition (WISCIII) tests as appropriate for age (Appendix). Patients and control subjects were scored for full-scale IQ, which reflected scores on verbal and performance subtests. All scores were normally distributed. The distribution and summary of the full-scale, verbal, and performance subtest scores are shown in Figure 3. Scores were significantly higher for control subjects than for patients (108.6 [SD 12] vs 101.9 [SD 13]; $P=.0007$, paired $t$ test), but both means were above the expected population mean (100 [SD 15]) using normative data. Therefore the statistically significant result might not be important clinically. The difference in full-scale score was due primarily to inequality in performance (112 [SD 14] vs 105 [SD 12]; $P=.002$, paired $t$ test) rather than verbal (103 [SD 17] vs 99 [SD 14]; $P=.174$, paired $t$ test) subtests.

We looked in further detail at the outcome of full-scale IQ testing, stratifying the comparison according to patient age. This was done by considering the younger group, who were suitable for evaluation with the Wechsler Preschool and Primary Scale of Intelligence (48-76 months, $\mathrm{n}=32$ ) apart from older children who were eligible for WISC-III (n
$=116)$. The difference in mean full-scale test scores in the younger patients was not statistically significant (108.9 [SD 13.9] vs 103.9 [SD $=12.3$ ]; $P=.359$, paired $t$ test). For the older patients assessed with the WISC-III protocol, the difference was statistically significant (108.5, [SD 12.2] vs 101.4 [SD 13.2]; $P=.001$, paired $t$ test). The performance subtest had a stronger contribution to this result than did the verbal subtest $(P=.0008$ vs $P=.021)$.

We examined the relationship between full-scale IQ score for patients and a number of variables relating to familial, preoperative, intraoperative, and perioperative factors, all considered to be of potential importance. The variables selected by means of the forward stepwise analysis $(P$ $=.05)$ are listed in Table 3 . Among those, the number of years of paternal education $(\beta=1.52)$, the perioperative detection of any neurologic abnormality perioperatively $(\beta$ $=-6.53)$, birth weight $(\beta=.005)$, and circulatory arrest time $(\beta=-5.50)$ had regression coefficients that were most likely to be different than zero $(P=.007, P=.08, P=$ .075 , and $P=.06$, respectively). Specifically, there was a loss of 6.5 IQ points if a neurologic deficit had been noted. When we assessed residuals, the multivariate $R^{2}$ value for the model was 0.13 , suggesting that only a small proportion of the variance in IQ scores could be accounted for by the variables examined. However, a plot of the residuals suggests that they were normally distributed and that the mode of analysis was appropriate to the data.

The Achenbach Child Behavior Checklist (Appendix) was used to allow parents to evaluate their child's activityrelated, social, school, and behavioral skills in 118 areas. We used raw scores for analysis, again comparing patients with "best-friend" control subjects (Table 4). Parents of the patients were more likely than parents of control subjects to perceive and report that their child had any type of behavioral problem $(P=.04)$, but this did not apply to difficulty 

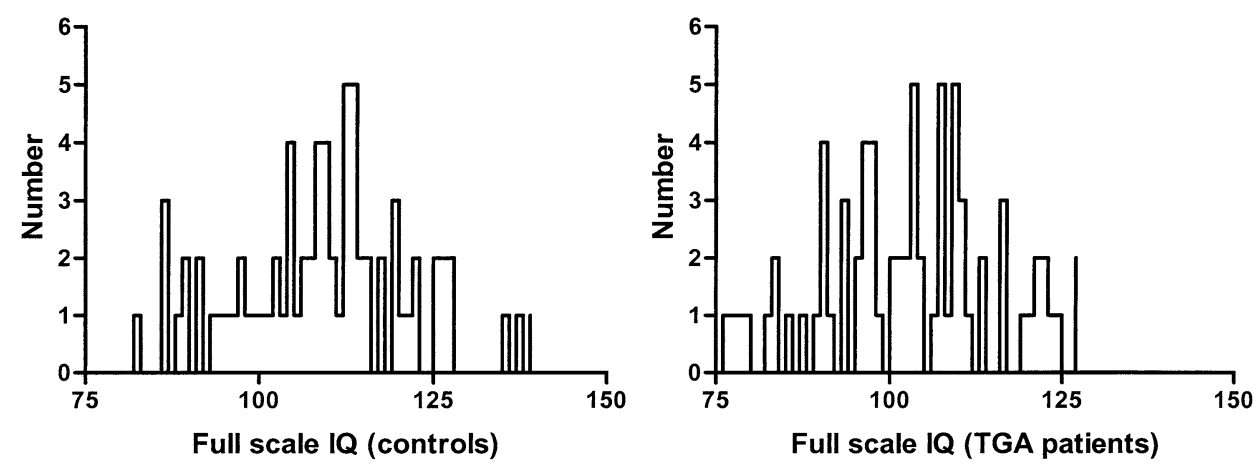

\begin{tabular}{|c|c|c|c|}
\hline IQ variable & Controls & TGA & $p$ (paired t-test) \\
\hline Full scale & $108.6, \mathrm{SD}=12$ & $101.9, \mathrm{SD}=13$ & 0.0007 \\
\hline Verbal & $103, \mathrm{SD}=17$ & $99, \mathrm{SD}=14$ & 0.174 \\
\hline Performance & $112, \mathrm{SD}=14$ & $105, \mathrm{SD}=12$ & 0.002 \\
\hline
\end{tabular}

Figure 3. Distribution of full-scale IO scores for patients and control subjects. The latter group scored higher, but the means for both groups fell in the normal range. The difference in full-scale score was related primarily to the performance rather than verbal subtest.

with activities or social skills $(P=.58)$. As a consequence, the total competence scores were lower (ie, worse) for patients than for control subjects $(P=.05)$.

We used the specifically designed Teacher Report Form to allow teachers who knew the study patients, control subjects, or both well to assess various aspects of schoolrelated behavior. This form is a companion to the Achenbach Child Behavior Checklist. Scores of 0,1 , or 2 were assigned for the 3 teacher-determined probability categories relating to each item, and the scores were analyzed nonparametrically. Teachers of patients were more likely than teachers of control subjects to suggest that there was a problem in motor aspects of speech $(P=.002)$, language expression $(P=.001)$, or learning ability $(P=.023$, Table 5). Patients were also more likely than control subjects to be perceived as being withdrawn $(P=.011)$, restless $(P=$ $.013)$, or inattentive $(P=.033$, Table 5$)$. The patients and control subjects were otherwise considered to be similar by their respective teachers.

\section{Discussion}

We have set out to compare our patients and control subjects in a number of areas, some objective and some more subjective. Both types of assessment are important because the way that we (health care workers) view our patients might not correspond to the perceptions of others (eg, parents and teachers) who know them better and who will interact with them in the longer term. Toward this end, the strategy of "best-friend" control subjects has been used in other noncardiac neonatal outcome studies and could be superior to comparisons involving siblings or normative population data. $^{21}$

Although the neurodevelopmental results in the cohort undergoing surgical intervention appear on average to be quite good, there are some aspects that suggest to us that these children might not be considered normal in all areas. In this respect our findings support those of other studies dealing with the same problem.

\section{Perioperative Events}

The neurologic substrate in infants undergoing cardiac surgery might be different than that of other neonates. Preoperative injury might be important in this regard. ${ }^{15,22}$ In a recent review of the preoperative status of 56 neonates with a variety of congenital cardiac lesions, more than half were found to have behavioral or neurologic abnormalities. In addition, $35.7 \%$ had microcephaly, and $12.5 \%$ had macrocephaly. ${ }^{15}$ Likewise, in our own series clinical seizure activity was more commonly observed preoperatively than postoperatively. The high incidence of preoperative problems might be important for later outcome, as noted in our own series and others. ${ }^{12}$ Although neonates with TGA-IVS rarely fall into a clearly definable genetic syndrome, congenital predisposition to neurologic injury or developmental delay could figure prominently as well. ${ }^{23}$ Thus a full assessment of the preoperative neurologic status is important for outcome analysis but at times is not possible because of the poor hemodynamic status, metabolic derangements, need for sedation and paralysis, and young age of the patients. 
TABLE 3. Variables selected for regression against fullscale 10 score beyond $\mathbf{4 8}$ months for patients undergoing ASO for TGA-IVS

\begin{tabular}{lcl}
\hline Independent variable & $\begin{array}{c}\text { Regression } \\
\text { coefficient }\end{array}$ & $\boldsymbol{P}$ \\
\hline Intercept & 86.3 & .0001 \\
Current age & -0.05 & .245 \\
Years of paternal education & 1.52 & .007 \\
Age at ASO & 0.12 & .09 \\
Birth weight & 0.005 & .075 \\
Circulatory arrest time & -5.50 & .061 \\
Perioperative neurologic problem & -6.53 & .08 \\
Preoperative P $\mathrm{P}_{2}$ & 0.18 & .362 \\
Postoperative BP (lowest) & -0.45 & .229 \\
Transport time & 0.02 & .3 \\
Vision problem at late follow-up & 6.46 & .147 \\
\hline
\end{tabular}

Additional variables entered into the initial equation included gestational age, Apgar score (1 and 5 minutes), CPB time, cardiac ischemic time, lowest temperature, days in the intensive care unit preoperatively, time on ventilator, lowest preoperative $\mathrm{P}_{2}$, lowest preoperative and postoperative $\mathrm{pH}$, lowest preoperative blood pressure, time from septostomy to surgical intervention, use of prostaglandin $\mathrm{E}_{1}$, cardiac arrest, days in hospital, mother's education level, parents' occupation, number of children in family, birth order, seizures perioperatively, any perioperative neurologic abnormality. $P$ is the probability that the coefficient differs from zero in the population.

$A S O$, Arterial switch operation; $B P$, blood pressure.

The incidence of all perioperative neurologic events observed in our patients is of concern, despite the fact that most events appeared to be relatively minor, self-limited, or both. Likewise, the finding of a higher head circumference profile in control subjects raises concerns about the possibility of structural damage, even if the TGA group has a mean and distribution similar to that of the normal population. This finding would need corroboration with specific structural investigations, such as magnetic resonance imaging, which was not done in our study. Because the appearance of neurologic abnormalities was predictive of a poorer performance on late IQ testing, these findings cannot be dismissed or trivialized, despite apparent patient recovery by the time of late follow-up. Others have noted a similar or higher incidence of acute neurologic events related to various types of cardiac operations in children. ${ }^{13}$

Miller and colleagues ${ }^{24}$ investigated 91 term infants who had cardiac surgery with low-flow CPB or DHCA, all at $15^{\circ} \mathrm{C}$ to $20^{\circ} \mathrm{C}$. At discharge, $19 \%$ had decreased alertness, $15 \%$ had seizures, and various other abnormalities were noted in a significant proportion. Decreased alertness, chorea, and hypotonia were more common with circulatory arrest times of greater than 60 minutes.

Fallon and coworkers ${ }^{12}$ noted neurologic problems (primarily seizures) in 31 of 523 children assessed early postoperatively. Arch anomalies requiring treatment were predictive of such events (16.6\% of cases). In the Fuller study
TABLE 4. Comparison of patients undergoing ASO for TGAIVS and "best-friend" control subjects by using the Achenbach Child Behavior Checklist (Appendix)

\begin{tabular}{lccl}
\hline Subtest & Patients & $\begin{array}{c}\text { Control } \\
\text { subjects }\end{array}$ & $\boldsymbol{P}$ \\
\hline Total competence & $15.7( \pm 3.3)$ & $16.9( \pm 3.5)$ & .05 \\
Activities & $5.5( \pm 1.8)$ & $6( \pm 1.9)$ & .1 \\
Social & $6.6( \pm 3.4)$ & $6.9( \pm 3.4)$ & .58 \\
Behavioral problem? & $33.3( \pm 18.7)$ & $26.7( \pm 19.4)$ & .04 \\
\hline
\end{tabular}

Total competence scores were worse for patients than for control subjects.

TABLE 5. Comparison of patients undergoing ASO for TGAIVS and "best-friend" control subjects by using the Teacher Report Form

\begin{tabular}{lc}
\hline Area of teacher assessment & $\begin{array}{c}\boldsymbol{P} \\
\text { (patients vs } \\
\text { control subjects) }\end{array}$ \\
\hline Vision & .405 \\
Hearing & .317 \\
Movement & .074 \\
Manipulation & .039 \\
Speech problem & .002 \\
Language expression problem & .001 \\
Language comprehension problem & .033 \\
Learning ability & .023 \\
Aggressive & .144 \\
Submissive & .083 \\
Attention seeking & .882 \\
Withdrawn & .011 \\
Restless & .013 \\
Inattentive & .033 \\
Does not mix (children) & .095 \\
Does not mix (adults) & .248 \\
\hline Scores & \\
\hline
\end{tabular}

Scores were assigned by teachers in various behavioral areas and then patients were compared with control subjects. Teachers of patients were more likely than teachers of control subjects to suggest that there was a problem in motor aspects of speech, language expression, or learning ability. Patients were also more likely than control subjects to be perceived as being withdrawn, restless, or inattentive.

6 of 19 patients available for long-term follow-up had persistent abnormalities that could have been related to perioperative events.

Newburger and associates ${ }^{3}$ conducted a prospective randomized trial in which neonates undergoing ASO were randomized to either low-flow $\left(50 \mathrm{~mL} \cdot \mathrm{kg}^{-1} \cdot \mathrm{min}^{-1}\right) \mathrm{CPB}$ or DHCA as the predominant strategy for intraoperative support. The overall incidences of clinical and EEG-detectable seizures in the circulatory arrest group were $11 \%$ and $26 \%$, respectively, in the first postoperative 48 hours. Patients undergoing DHCA had a higher incidence of clinical or EEG-detectable ictal activity (odds ratio, 4.4 and 2.5, respectively). The results were similar when DHCA dura- 
tion (as opposed to use) was used as the dependent variable for EEG seizure probability, and in this respect there did not appear to be a completely safe duration of circulatory arrest. In our own study the incidence of perioperative clinical seizure activity was $6.8 \%$ (95\% CI, $2 \%-15 \%$ ). If patients who had seizure activity before ASO are excluded, then the incidence decreases to $1.4 \%$ (95\% CI, 0\%-7\%). Because EEG monitoring was not routinely used (especially during periods of paralysis and narcosis), the true prevalence of ictal activity in our patients is unknown and, of course, is likely to have been understated. This is compounded by the retrospective nature of the data collection. No choreoathetosis was observed in our patients.

\section{Late Neurodevelopmental Status}

When patients in the Boston study cited above were reevaluated at 1 year, the use of circulatory arrest predicted lower indices by using the Bayley Scales of Infant Development $(P=.01) .{ }^{25}$ The scores decreased with DHCA duration, as the risk of finding any neurologic abnormality increased. Perioperative seizures were associated with lower IQ scores and an increased likelihood of magnetic resonance imaging abnormalities. As in our own study, however, perioperative seizures did not predict seizure activity later in life.

At 4 years of age, the full Boston study cohort was somewhat below expectation in IQ, expressive language, visual-motor integration, motor function, and oromotor control. ${ }^{26}$ DHCA did not, however, predict a lower IQ score. The IQ mean of $92.6 \pm 14.7$ decreased slightly below the population mean $(P<.001)$. As in our own study, social aspects (paternal education in the Royal Children's Hospital group) were thought to explain an important fraction of IQ variation. Also, at 4 years, $28 \%$ of patients were believed to have a possible neurologic abnormality, and $30 \%$ had a definite abnormality. Perioperative seizure activity predicted a loss of full-scale IQ (12.6 points for clinical seizures and 7.7 points for EEG-detected seizures).

The differences between patients and control subjects in our study were more important in the older patients than in the younger ones. This is concordant with the known relative lack of predictive value of IQ testing in very young children, and thus the finding might be of clinical significance as well. However, without longitudinal assessment of the same patients, the importance of this finding is difficult to establish.

Our study results support those of the Boston investigators because for our patients, the presence of any perioperative neurologic abnormality was inversely related to IQ test scores after 48 months (loss of 6.5 IQ points). Taken as an isolated variable, seizure activity did not predict poorer IQ test results in our patients, but the small number of patients $(\mathrm{n}=5)$ would not have provided sufficient power to detect this relationship with confidence. By using the high-flow
CPB strategy with limited circulatory arrest, however, no CPB-related parameter, including arrest time, appeared to influence this outcome.

\section{Use of DHCA and Late IQ}

Low full-scale IQ scores have been reported after operations for various congenital heart lesions, in most cases for operations performed with low-flow CPB or DHCA., ${ }^{2,4-7}$ The results have been variable, however, as might be expected when diverse perioperative strategies are used in multiple institutions. Whether all of these findings can be generalized to the ASO is debatable, even though the converse seems more likely.

Mahle and colleagues ${ }^{4}$ looked at 115 school-age $(9 \pm 2$ years) children with hypoplastic left heart syndrome (HLHS; all survivors of the Norwood sequence with DHCA). The median full-scale IQ was 86 points (range, 50-116 points). Eighteen percent had an IQ score of less than 70, and a lower IQ score was predicted by the presence of perioperative seizures. Kern and associates ${ }^{8}$ investigated 14 HLHS survivors older than 3 years of age. The full-scale IQ score was 88 , with an adaptive behavior score of 91 (normal, $100 \pm 15$ ). There was a negative correlation of DHCA time and full-scale IQ. After surgical intervention for HLHS, pathologic studies of the brains of nonsurvivors have suggested that a DHCA time of greater than 40 minutes was associated with the presence of certain acquired brain lesions. ${ }^{16}$

In a recent study from Oates and coworkers, ${ }^{1}$ IQ was measured in 114 children 9 to 10 years after operations for cyanotic and acyanotic heart disease. The analysis suggested a loss of 3 to 4 IQ points per 10 minutes of DHCA arrest time. The inverse relationship of IQ to arrest time ( $P$ $=.002)$ was similar for both verbal and performance subtests.

Haneda and colleagues ${ }^{9}$ reported results of IQ testing for 161 infants and children undergoing a variety of cardiac surgical procedures at a mean age of 3.6 years, using preoperative IQ test results as the control. Although overall there was no change in developmental quotient or IQ, patients who had a DHCA arrest time of greater than 50 minutes showed a significant decrease in IQ scores.

Clarkson and associates ${ }^{10}$ analyzed 76 long-term survivors of cardiac operations performed at 4 days to 26 months with DHCA. At late follow-up, the mean IQ was $92.9 \pm$ 16.5, with no relation of scores to duration of DHCA. Low birth weight for gestational age, preoperative neurologic problems, and low socioeconomic status all had better predictive value for lower IQ scores.

DHCA is a useful and time-honored tool for pediatric cardiac surgeons, but patients for whom this strategy remains essential constitute a vanishing cohort. Whether there is a completely safe duration of DHCA remains a subject of 
debate. In the current era, however, the benefit of circulatory arrest might be greater for the surgical team than for the patient. Since 1994, the authors have not routinely used circulatory arrest for any part of the ASO for TGA-IVS. The current strategy is full-flow CPB at greater than $28^{\circ} \mathrm{C}$ with bicaval cannulation. This change in technique has not compromised our ability to achieve a good technical repair. ${ }^{17}$ This has also been the case for other lesions requiring neonatal repair, notably aortic arch reconstruction. Whether this strategy will improve long-term outcome remains to be seen.

\section{Limitations of the Present Study}

1. Our study is retrospective.

2. Not all eligible patients could be assessed, although we could not identify any reason that this might skew the population or introduce any type of bias.

3. The use of "best-friend" control subjects has the potential problem of matching children with similar IQ scores and social skills. This effect is amortized by the tendency for friendships to develop on the basis of geographic proximity in the age groups under consideration. In any case, any type of control group will present limitations in a study of this type.

4. Intelligence is not a fixed biologic trait but relates to experience and thus can evolve over time. The correlation of infant, child, and adult scales might not be strong. Our study was neither prospective nor longitudinal, and further assessment over time will be required. This is true for most other published studies.

5. Detailed preoperative neurologic assessment was not consistently available because some patients were sedated, paralyzed, and ventilated or otherwise not easily assessed before the operation. This limitation is not unique to our study but is a common feature in this type of outcome analysis.

6. EEG monitoring, chromosomal analysis, and neurologic imaging were not consistently used during the course of this study. It is possible that identification of clinically silent ictal activity could have altered some of the inferences.

7. All patients in the study had at least a brief period of circulatory arrest, although at a higher temperature $\left(22^{\circ} \mathrm{C}\right)$ than that required for longer DHCA times. The findings might have been strengthened if neither circulatory arrest nor low flow had been used, as is our current practice. To further validate our conclusions, contemporary groups of patients operated on with DHCA and low-flow CPB in our own institution would have been needed. It is unlikely that even a prospective study of this type could be conducted in light of current evidence regarding DHCA.

8. Factors other than the conduct of CPB might be important to the outcome of TGA surgery, as well as for all other congenital cardiac problems.

\section{Conclusions}

By using a strategy of full-flow CPB with minimal circulatory arrest, the risk of perioperative neurologic abnormalities was low but not insignificant. The perioperative factors analyzed, including those relating to CPB and DHCA time, did not have strong predictive value for perioperative neurologic events. Although patients scored lower then control subjects on IQ testing at late follow-up, the IQ scores for both groups fell within the normal range. The presence of a perioperative neurologic deficit was predictive of poorer IQ test results, but other factors analyzed (excepting level of paternal education) did not have strong predictive value. Patients were more likely to have mild abnormalities at late neurologic assessment, but there was not a strong trend for involvement of any specific area of function. The parents and teachers of patients were more likely to perceive a social or behavioral problem. The general development and freedom from continued medical care, drug therapy, and extracardiac problems are similar for the patients and control subjects. With objective consideration, these results probably cannot be interpreted as clinically or statistically better than those in other published series in which different bypass strategies were used. Thus although the continued use of full-flow CPB with minimal or no circulatory arrest is justified by the findings of this study, further investigation and refinement will be important for achieving optimal neurodevelopmental outcome.

\section{References}

1. Oates RK, Simpson JM, Tumbull JAB, Cartmill TB. The relationship between intelligence and duration of circulatory arrest with deep hypothermia. $J$ Thorac Cardiovasc Surg. 1995;110:786-92.

2. Bellinger DC, Jonas PA, Rappaport LA, Wypij D, Wernovsky G, Kuban KCK, et al. Developmental and neurologic status of children after heart surgery with hypothermic circulatory arrest or low-flow cardiopulmonary bypass. N Engl J Med. 1995;332:549-55.

3. Newburger JW, Jonas PA, Wernovsky G, Wypij D, Hickey PR, Kuban $\mathrm{KCK}$, et al. A comparison of the perioperative neurologic effects of hypothermic circulatory arrest versus low-flow cardiopulmonary bypass in infant heart surgery. $N$ Engl J Med. 1993;329:1057-64.

4. Mahle WT, Clancy RR, Moss E, Gerdes M, Jobes DR, Wernovsky G. Neurodevelopmental outcome and lifestyle assessment in school age and adolescent children with hypoplastic left heart syndrome. Pediatrics. 2000;105:1085-92.

5. Rogers BT, Msall ME, Buck GM, Lyon NR, Norris MK, Roland JM, et al. Neurodevelopmental outcome of infants with hypoplastic left heart syndrome. J Pediatr. 1995;126:496-8.

6. Gomelsky A, Holden EW, Ellerbeck KA, Brenner JI. Predictors of developmental outcomes in children with complete transposition. Cardiol Young. 1998;9:352-7.

7. Hovels-Gurich HH, Seghaye MC, Dabritz S, Messmer BJ, von Bernuth G. Cognitive and motor development in preschool and schoolaged children after neonatal arterial switch operation. J Thorac Cardiovasc Surg. 1997;114:578-85.

8. Kern JH, Hinton VJ, Nereo NE, Hayes CJ, Gersony WM. Early developmental outcome after the Norwood procedure for hypoplastic left heart syndrome. Pediatrics. 1998;102:1148-52.

9. Haneda K, Itoh T, Togo T, Ohmi M, Mohri H. Effects of cardiac surgery on intellectual function in infants and children. Cardiovasc Surg. 1996;4:303-7.

10. Clarkson PM, MacArthur BA, Barratt-Boyes BG, Whitlock RM, 
Neutze JM. Developmental progress after cardiac surgery in infancy using hypothermia and circulatory arrest. Circulation. 1980;62:85561.

11. Kirkham FJ. Recognition and prevention of neurological complications in pediatric cardiac surgery. Pediatr Cardiol. 1998;19:331-45.

12. Fallon P, Aparicio JM, Elliott MJ, Kirkham FJ. Incidence of neurological complications of surgery for congenital heart disease. Arch Dis Child. 1995;72:418-22.

13. Rappaport LA, Wypij D, Bellinger DC, Helmers SL, Holmes GL, Barnes PD, et al. Relation of seizures after cardiac surgery in early infancy to neurodevelopmental outcome: Boston circulatory arrest study group. Circulation. 1998;97:773-9.

14. Alden B, Gilljam T, Gillberg C. Long-term psychological outcome of children after surgery for transposition of the great arteries. Acta Paediatr. 1998;87:405-10.

15. Limperopoulos C, Majnemer A, Rosenblatt B, Shevell M, Rohlicek C, Tchervenkov C. Multimodality evoked potential findings in infants with congenital heart defects. J Child Neurol. 1999;11:702-7.

16. Karl TR. Transposition of the great arteries. In: Nichols DG, Cameron DE, eds. Critical cardiac disease in infants and children. St Louis: Mosby Year Book; 1994. p. 825-40.

17. Davis AM, Wilkinson JL, Karl TR, Mee RB. Transposition of the great arteries with intact ventricular septum: arterial switch repair in patients 21 days of age or older. J Thorac Cardiovasc Surg. 1993;106:111-5.

18. Karl TR, Cochrane A, Brizard CP. Arterial switch: surgical solutions to complex problems. J Tex Heart Inst. 1997;24:322-33.

19. Mee RBB. The arterial switch operation. In: Stark J, de Leval MR, editors. Surgery for congenital heart defects. London: WB Saunders; 1994. p. 483-500.

20. Agresti A. Analysis of ordinal categorical data. Wiley: New York; 1984.

21. Hack M, Taylor HG, Klein N, Eiben R, Shatschneider C, MercuriMinich N. School age outcomes in children with birth weights under 750g. N Engl J Med. 1994;331:753-9.

22. Glauser TA, Rorke LB, Weinberg PM, Clancey RR. Congenital brain anomalies associated with the hypoplastic left heart syndrome. Pediatrics. 1990;85:984-90.

23. Gerdes M, Solot C, Wang PP, Moss E, LaRossa D, Randall P, et al. Cognitive and behavior profile of preschool children with chromosome 22q1 1.2 deletion. Am J Med Genet. 1999;85(2):127-33.

24. Miller G, Eggli KD, Contant C, Baylen BG, Myers JL. Postoperative neurologic complications after open heart surgery on young infants. Arch Pediatr Adolesc Med. 1995;149:764-8.

25. Bayley N. Manual for the Bayley Scales of Infant Development. 2nd ed. San Antonio, Tex: Psychological Corp; 1993.

26. Bellinger DC, Wypij D, Kuban KCK, Rappaport LA, Hickey PR, Wernovsky G, et al. Developmental and neurological status of children at 4 years of age after heart surgery with hypothermic circulatory arrest or Iow-flow cardiopulmonary bypass. Circulation. 1999;100:526-32.

\section{Appendix: Neurodevelopmental Assessment Instru- ments Used in This Study}

\section{Wechsler Intelligence Scale for Children-Third Edition (WISC-III)}

This test is a downward extension of adult intelligence scales and the most widely used test for children aged 6 to 17 years. ${ }^{1}$ It consists of 13 subtests ( 6 verbal and 7 performance). The emphasis is on the global nature of intelligence, and no one facet is overemphasized. Full-scale, verbal, and performance scores are generated. Reliability has been well validated. Scores of greater than 120 are considered superior, and those less than 70 are indicative of mental retardation. A score of 90 to 109 is the average range.
Wechsler Preschool and Primary Scale of Intelligence This test is a further downward extension of the Wechsler scales for use in children 3 to 6 years of age. ${ }^{2}$ The test is designed to produce results interpretable in the same context as those of the WISC-III. The design takes into account generation of interest among young children. Standardization and interpretation are well validated.

\section{Achenbach Child Behavior Checklist (CBCL)}

This is an instrument suitable for behavior analysis in children ages 4 to 18 years. ${ }^{3}$ The CBCL/4-18 (suitable for 4 - to 18 -year-old subjects) obtains parents' reports of children's competence and behavioral-emotional problems. Parents provide information for 20 competence items covering their child's activities, social relations, and school performance. The CBCL/4-18 has 118 items that describe specific behavioral and emotional problems plus 2 openended items for reporting additional problems. The scales are based on principal component analyses of parents' ratings of 4455 clinically referred children and are normed on 2368 children aged 4 to 18 years. The normative sample was representative of the 48 contiguous states for socioeconomic status, ethnicity, region, and urban-suburban-rural residence. Children were excluded from the normative sample if they had been referred for mental health or special education services within the past year. The CBCL/4-18 Total Problems score has a 1-week test-retest reliability $r$ value of 0.93 , whereas the interparent agreement is an $r$ value of 0.76 .

\section{Movement Assessment Battery for Children (Movement ABC)}

This is a non-sex-specific standardized test of children's motor skills devised by Henderson and Sugden. ${ }^{4}$ It measures motor skills that are needed on an everyday basis, some of which will have educational significance. The test is appropriate from age 4 years onward and is administered at a level appropriate for the child's age. The test is divided into 3 main areas: manual dexterity, ball skills, and balance. The higher the score, the greater the impairment. A score of greater than 13 for children older then 6 years and a score of greater than 16.5 in 4- to 5-year-old children is indicative of a definite motor problem.

\section{Appendix References}

1. Wechsler D. Wechsler intelligence scale for children. 3rd ed. San Antonio (TX): The Psychological Corp; 1991.

2. Wechsler D. Wechsler preschool and primary scale of intelligence-revised. San Antonio (TX): The Psychological Corp; 1991.

3. Achenbach TM, Edelbrock CS. Manual for the Child Behavior Checklist and the Revised Child Behavior Profile. Burlington (VT): University Associates in Psychiatry; 1983.

4. Henderson SE, Sugden DA. Movement Assessment Battery for Children. London: The Psychological Corp; 1992. 